\title{
“ACHO QUE JÁ NÃO VOU EMBORA COMO ENTREI..." IMPLICAÇÕES EPISTEMOLÓGICAS, METODOLÓGICAS E DEONTOLÓGICAS DA ENTREVISTA DE HISTÓRIA DE VIDA
}

\author{
“I DON’T THINK I'M GOING TO LEAVE AS I CAME IN..." \\ EPISTEMOLOGICAL, METHODOLOGICAL AND \\ DEONTOLOGICAL IMPLICATIONS OF THE LIFE-STORY \\ INTERVIEW
}

\author{
Ana Maria Brandão \\ Departamento de Sociologia, Instituto de Ciências Sociais, Universidade do Minho \& Centro Interdisciplinar de \\ Ciências Sociais - Polo da Universidade do Minho (CICS.NOVA.UMinho). Campus de Gualtar, 4710-057 Braga, \\ Portugal. Email: anabrandao@ics.uminho.pt
}

\begin{abstract}
Resumo: A vida narrada nunca corresponde à vida vivida. Ela implica uma reinterpretação das ocorrências passadas, da sua sequência e da sua relevância a partir do presente. Especialmente quando essa narrativa é solicitada, somos levados a encontrar ou criar ligações, a recordar algo esquecido, a lê-lo noutros moldes. Neste artigo, refletimos sobre algumas implicações epistemológicas, metodológicas e deontológicas da entrevista de história de vida no que respeita aos efeitos pessoais e emocionais da rememoração, de interrupção da durée, de reorganização de eventos e/ou significados e ao risco de imposição de problemática. Para tal, mobilizamos dados de entrevistas cujo guião incluiu questões que tiveram como objeto a própria entrevista. Se, do ponto de vista teórico e epistemológico, a opção pela história de vida requer o reconhecimento da sua natureza própria, do ponto de vista da técnica, a autovigilância e as regras da deontologia profissional constituem balizas importantes para o/a investigador/a.
\end{abstract}

Palavras-chave: história de vida, epistemologia e metodologia, deontologia, sociologia.

\begin{abstract}
A life-story never corresponds to the life a person actually lived. Recollecting a life is always a current reinterpretation of past events, their sequence and relevance. Especially when such narrative is requested, we are led to find or create associations, to remember the forgotten, to read it in alternative ways. In this article, we reflect on some epistemological, methodological and deontological implications of the life-story interview with regard to personal and emotional effects of recollection, interruption of durée, reorganization of events and / or meanings and the risk of imposing problems to the storyteller. To this end, we mobilized data from interviews whose script included questions that took the interview as the object of analysis. If, from a theoretical and epistemological point of view, the life-story interview requires acknowledging its particular nature, from a technical point of view, self-surveillance and the rules of professional ethics are important guidelines for the researcher.
\end{abstract}

Keywords: life-story interview, epistemology and methodology, deontology, sociology.

\section{Introdução}

As histórias são um elemento definidor da cultura. Elas servem a ambição de ordenação da experiência, de atribuição de sentido e de preservação da existência. 
Obedecem a estruturas e estilos narrativos próprios, ligados aos momentos e contextos particulares em que são geradas. Qualquer história é, assim, um registo da sua época - de como ela foi/ é vivida, pensada e sonhada - e um guião, que pode servir diferentes desígnios - interpretar, orientar, reafirmar, incluir ou excluir, confortar ou confrontar, questionar, curar.

De todas as histórias que povoam o mundo, há histórias que nos ligam a ele de forma especial: são as histórias que contamos acerca de nós próprios, as histórias das nossas vidas. Ao mesmo tempo, a experiência subjetiva nunca é puramente individual: ela traduz também uma experiência comum, social ou coletiva (Hoerning \& Alheit, 1995). Assim, as histórias de vida, além de traduzirem a experiência e a verdade dos/as seus/suas narradores/as, permite perceber como é que elas são construídas na ligação ao Outro, a um contexto, às suas convenções e às meta-narrativas que o caracterizam (Plummer, 2001). O recurso às histórias de vida atende, neste quadro, não tanto à sua conformidade a experiências de vida particulares, mas mais à produção e ao uso de certas narrativas não só pelos sujeitos cujas vidas se toma em consideração, mas também por outros, com vários fins descritivos e/ ou explicativos (Atkinson, 2002, p. 124).

Atkinson (2002, p. 125) definiu a história de vida como a história que uma pessoa decidiu contar acerca da vida que viveu, aquilo que ela recorda desta e o que ela quer que os outros saibam acerca dela, em suma, a essência narrativa do que lhe aconteceu. Entendida neste sentido, a história de vida levanta diversas questões de ordem epistemológica e metodológica, mas também deontológica. Neste artigo, reflete-se sobre as implicações da entrevista de história de vida para a investigação sociológica, particularmente no que se refere aos fenómenos da interrupção da durée, da reorganização de eventos e/ ou significados, ao risco de imposição de problemática e aos efeitos emocionais e pessoais da rememoração.

O material empírico mobilizado refere-se a um total de dezoito entrevistas de história de vida, realizadas entre 2003 e 2005, no quadro de uma dissertação de doutoramento que teve como objeto o processo de construção social de identidades de um conjunto de mulheres envolvidas em relações de carácter homoerótico (Brandão, 2010). As entrevistas, de carácter semidiretivo, foram realizadas a mulheres que, à data da entrevista, tivessem mantido pelo menos uma relação amorosa com outra mulher, independentemente das suas identidades reclamadas. O guião de entrevista, adaptado das propostas de Charmaz (2002), incluía, no final, duas questões de encerramento que incidiam especificamente sobre a própria entrevista e os seus efeitos, a saber: "Há alguma coisa que lhe tenha ocorrido durante esta entrevista acerca da qual nunca tivesse pensado antes?", "Há alguma questão que me queira colocar ou algum comentário que queira fazer?". Os excertos 
apresentados ${ }^{1}$ referem-se, na sua maioria, às respostas a estas questões, mas também a comentários que as entrevistadas fizeram ao longo da entrevista suscetíveis de ser enquadrados no tema deste artigo. A técnica de tratamento usada foi a análise de conteúdo temática, tendo os temas sido identificados a partir da análise do texto transcrito da entrevista e não em obediência a uma grelha categorial predefinida. As entrevistadas são identificadas pelo pseudónimo, idade à data da entrevista e grau de escolaridade.

\section{O interesse pela história de vida como material empírico: Breve nota de enquadramento}

As histórias de vida que servem de base a este artigo foram recolhidas com dois propósitos específicos: compreender em que medida o reconhecimento consciente de uma atração homoerótica desencadeia, ou não, alterações na identidade pessoal reclamada e quais as condicionantes sociais desse processo. São histórias que se inscrevem, ao nível macrossociológico, nas duas tendências de longa duração para a individualização e psicologização da vida social (Elias, 1989; Giddens, 1997) e para a transformação do self num projeto reflexivo (Giddens, 1997). Ao mesmo tempo, elas refletem o processo de autonomização da sexualidade como domínio de saber pericial e de atribuição de sentido e a centralidade que veio a assumir na identidade pessoal, social e coletiva (Foucault, 1994; Giddens, 1997).

$\mathrm{O}$ interesse pela história de vida centrou-se, primeiramente, na história das individualidades, das grandes personagens históricas, frequentemente sob a forma da biografia ou autobiografia, passando, gradualmente, para um enfoque nas vidas dos anónimos (cf. Bertaux, 1997; Plummer, 2001). Esta viragem tem sido explicada pela necessidade e/ ou pela vontade de dar voz aos que a não têm, aqui incluídas as minorias sexuais, e torna-se visível nas Ciências Sociais a partir das décadas de 1960/70 (Chamberlayne, Bornat \& Wengraf, 2000; Plummer, 2001; Polletta, Chen, Gardner \& Motes, 2011). Embora o interesse da Sociologia pela história de vida remonte ao estudo inaugural de Thomas e Znaniecki (1918-1920), The Polish Peasant, é também sensivelmente na mesma altura que o interesse pelas histórias das pessoas comuns se acentua ${ }^{2}$.

No caso particular das minorias sexuais - e mais especificamente da população gay e lésbica - , como material empírico principal ou complementar, recolhidas através de entrevista e/ou da análise documental, as histórias de indivíduos particulares têm permitido traçar a história da(s) sua(s) subcultura(s) e da(s) sua(s) comunidade(s), seja por via da elaboração de modelos de desenvolvimento da identidade pessoal e/ou social, seja pela reconstituição dos seus processos de formação, 
consolidação e mobilização política ${ }^{3}$. Funcionando frequentemente como instrumento de denúncia do preconceito, da desigualdade, enfim, da descriminação, tem sido salientado que essas histórias permitem também a identificação, promovem a coesão de grupo e consolidam a ideia de uma história comum (cf. Demory \& Pullen, 2012; Norton, 2016; Plummer, 2002; Polletta, Chen, Gardner \& Motes, 2011). Ao mesmo tempo, assumem a forma de guiões e, neste sentido, ao efeito libertador que lhes é atribuído, soma-se o de conformação. Assim, as histórias de "saída do armário" de gays e lésbicas, a que Ponse (1978) chamou a "trajetória gay", são ilustrativas dessa tensão: criando regras de enunciação do discurso da própria comunidade gay e lésbica, a linearidade e o sentido relativamente unívoco que apresenta nunca corresponde com exatidão às biografias reais. Mais do que isso, como sublinha Chauncey (1998), o significado da expressão tem designado coisas muito diferentes desde a primeira metade do século XX.

Em todo o caso, esse duplo efeito mostra bem que as histórias narradas obedecem a convenções e estilos narrativos particulares que revelam as características de uma época, de uma sociedade, de uma cultura. É assim que a investigação tipicamente baseada em entrevistas de história de vida de gays e lésbicas no ocidente economicamente desenvolvido parece estar a perder importância, centrando-se agora mais na análise da sua presença noutros suportes e formas de representação, como sejam os meios de comunicação de massas (e.g., Demory \& Pullen, 2012), ou no estudo de subcategorias particulares, como sejam os/as gays e lésbicas idosos/as (e.g., King, 2016). Ao mesmo tempo, assistimos à publicação de investigação assente nas histórias de vida de gays e lésbicas em países do Leste europeu, islâmicos ou mesmo africanos, como atesta uma rápida consulta em linha 4 .

A relevância da história de vida é, pois, dupla: social e política, por um lado, e sociológica, por outro.

O interesse pelas histórias de vida tem estado, enfim, na origem de um conjunto relativamente vasto de publicações, incluindo diversas obras de carácter metodológico. Porém, com a possível exceção do trabalho continuado de Plummer (1993, 2001, 2002), que privilegia as mudanças nos/as protagonistas, conteúdos, convenções narrativas e condições de produção das histórias, a generalidade das obras publicadas concede maior atenção à natureza particular da história de vida, às condições de aplicação das técnicas de recolha e tratamento, aos efeitos da interação entre investigador/a e investigado/a e aos princípios éticos que devem orientar a sua recolha e utilização (e.g., Atkinson, 2002; Bertaux, 1997; Caetano, 2015; Denzin, 1989; Gubrium \& Holstein, 2002; Lieblich, Zilber \& Tuval-Mashiach, 2008; Roulston, 2014; van der Maren, 2010). Em geral, a reflexão desenvolve-se num plano relativamente abstrato e formal, não recorrendo diretamente à exposição das 
apreciações dos/as entrevistados/as acerca do próprio procedimento de recolha. Nas seç̧ões que se seguem, procuramos ilustrar alguns desses efeitos, colocando, precisamente, em primeiro plano, essas apreciações.

\section{Interrupção da durée, reorganização de eventos e risco de "imposição de problemática" ou a natureza processual da história de vida}

A situação formal de entrevista é uma situação atípica. Ela traduz-se, invariavelmente, numa interrupção da durée, aqui entendida no sentido Bergsoniano como "a forma que a sucessão dos nossos estados de consciência adquire quando o nosso eu se deixa viver, quando não estabelece uma separação entre o estado presente e os anteriores" (Bergson, 1988, p. 72). Pelo contrário, a entrevista implica uma quebra nas rotinas quotidianas do/a entrevistado/a, constituindo-se como um momento de "retrospeção interpretativa" que torna visíveis "as alternativas genuínas", mas que apenas tem lugar, como sublinha Schütz (2001, p. 347), "quando os atos já foram conseguidos e (...) o tornar-se foi traduzido em existência". Isto é especialmente visível na verbalização consciente de um "corte" no tempo vivido, decorrente diretamente da questão colocada pelo/a entrevistador/a ou indiretamente da reflexão e do autoquestionamento que suscita da parte do/a entrevistado/a, como ilustra o excerto seguinte:

Parei. Parei para pensar como é que é ser homossexual e por que é que sou e por que é... Uma coisa que eu não faço. Tê-lo-ei feito há alguns anos atrás. Hoje, não o faço... É tão natural, (...) que só mesmo para uma coisa destas... Parar para pensar como é... No meu dia-a-dia, não o faço. Não me questiono. Nem me interrogo como é que é, como seria se não fosse...

(Margarida, 33 anos, frequência de licenciatura)

Os efeitos do corte na durée evocam, ainda que de forma mais implícita do que explícita, o clássico problema de "imposição de problemática" ao confrontar os indivíduos com "questões que a sua experiência não lhes coloca" (Bourdieu, Chamboredon \& Passeron, 1983, p. 57 e ss.) e/ ou com "uma estruturação de problemas que não é a sua", arrastando o risco de "estimular a produção respostas meramente reactivas às hipóteses previstas" (Ferreira, 1987, p. 170). Mas mesmo quando as respostas não decorrem da questão colocada ou dos moldes em que é enunciada, elas não deixam de ser afetadas pelo próprio exercício reflexivo que o/a entrevistado/a é chamado a fazer, especialmente no caso da entrevista de história de vida (cf. Caetano, 2015, p. 6). 
Ao contar a sua história, a pessoa recorda-a, mas também a (re)descobre e (re)faz. A vida narrada nunca corresponde, por isso, exatamente à história vivida quer em termos da sua conformidade a eventos reais, quer da sua sequência efetiva, quer dos seus significados. Ela envolve sempre uma reinterpretação das ocorrências passadas, da sua sequência e da sua relevância a partir do ponto de vista atual e das visões de futuro do/a seu/sua narrador/a (Atkinson, 2002; Bertaux, 1997; Dwivedi \& Gardner, 2000; van der Maren, 2010). Por essa razão, este/a é levado/a a encontrar ou a estabelecer novas ligações entre eventos vividos e o próprio sentido que lhes é atribuído sofre uma modificação. Isto mesmo é ilustrado pelas palavras de Leonor quando reflete sobre os efeitos dos seus envolvimentos amorosos com outras mulheres:

Pensei agora mesmo! Pensei agora mesmo se eu considero isto uma cruz. Embora eu tenha dito: 'Não é nenhuma cruz que eu carrego', ao mesmo tempo, pensei: 'Será que não é?' Porque, durante muito tempo, eu vivi uma vida dupla que era em casa e na rua. (...) Pensei que, se calhar, é uma cruz que eu carrego!

(Leonor, 35 anos, $12 .^{\circ}$ ano)

O carácter processual da história de vida remete, ainda, para a questão da proximidade deste tipo de entrevista com a entrevista psicoterapêutica (cf. Dwivedi, 2000; de Gaulejac \& Legrand, 2012). Com efeito, a própria entrevista de história de vida pode constituir-se como um momento de "síntese do Ego" (Erikson, 1980), um "processo de totalização" (Tap, 1981, 1996) através do qual readquirimos o sentimento de continuidade e permanência através da reelaboração da história que sustenta a nossa identidade. Ela pode, assim, contribuir para que o/a entrevistado/a (re)tome o fio condutor da sua existência, atribuindo-lhe um sentido mais ou menos coerente, porém, sem que isso elimine o seu potencial simultaneamente desorganizador. É interessante, aliás, notar que algumas entrevistadas que tinham já recorrido à terapia, evocaram, elas próprias, esse paralelismo: “É engraçada, essa pergunta! Até é um bocadinho terapêutica. Esta entrevista até está a ser um bocadinho terapêutica, dá para organizar algumas ideias e para organizar as coisas... Acho que já não vou embora como entrei..." (Marisa, 37 anos, licenciatura)

Mas o paralelismo está também presente, ainda que não verbalizado do mesmo modo, nas que não passaram por tal experiência:

(...) a questão dos meus amigos e a questão de termos, de certa forma, dois mundos separados. Se calhar, nem pensava nisso de uma forma tão clara para mim. (...) O próprio facto de pensar sobre as coisas acaba por dar algum significado, nem que seja no sentido de restruturar algumas ideias e ver como é que as coisas se encadearam. É interessante, mas eu precisava de mais uma entrevista para me organizar.

(Luísa, 24 anos, frequência de licenciatura) 
Isto está a fazer-me pensar nalgumas coisas em que já não pensava há muito tempo, em que nunca tinha pensado... Uma coisa é certa: estas duas conversas ajudaram-me a verbalizar algumas coisas que eu achava que não estavam bem em mim, mas ajudaram-me a confirmar. O passar para a palavra obrigou-me a ver se eu tinha a certeza ou não, se já a sinto, e isso ajudou-me a avançar mais um pouco.

(Alexandra, 37 anos, licenciatura)

Sendo a história de vida uma reconstrução do passado, mais do que o relato fiel do que aconteceu, como e quando (Ponse, 1978, p. 159), quando é solicitada, a interferência do/a investigador/a e do quadro de análise que transporta consigo é incontornável, estando presente nas perguntas que faz e no rumo que dá à conversação, mas também nos efeitos mais ou menos imprevistos que produz. Ora, como sublinha Ferreira (1987, p. 170), "A única solução para atenuar os efeitos da diretividade tem que passar forçosamente pela autorreflexão do investigador sobre as determinações da sua própria problemática e, sobretudo, considerar esses efeitos nas respostas obtidas no momento da sua interpretação". A presença de um guião, por muito reduzido que seja o seu grau de diretividade, tem efeitos naquilo que é contado, no modo como é contado e no sentido que lhe é atribuído, aspetos que reforçam a necessidade de autovigilância.

Para além da necessária reflexão crítica acerca dos procedimentos metodológicos, incluindo o processo de construção dos guiões e as condições da sua aplicação, quando a questão é a da correspondência entre a vida narrada e a vida vivida, têm sido sugeridas estratégias várias de verificação, que incluem, por exemplo, reformulações do tema no decurso da conversação, voltar a interrogar o/a narrador/a passado algum tempo ou o recurso a outras fontes, em qualquer caso tendo em vista a aferição da consistência interna e externa da narrativa recolhida (cf. Atkinson, 2002, pp. 132-136; Bertaux, 1997, pp. 65-105).

Nem sempre, todavia, o propósito da investigação reside na verificação desse estatuto de veracidade factual. É possível usar os dados recolhidos para chegar às verdades e às interpretações que os atores fazem das suas próprias experiências e das lógicas que presidem a esse processo. A questão não é, então, a de saber se a coerência biográfica é uma ilusão, como pretende Bourdieu (1986), ou uma realidade, mas a de saber como é que os atores atribuem coerência às suas vidas quando as narram e que ideologias mais vastas subjazem às e estruturam as suas narrativas.

Não está, portanto, necessariamente, em causa a dimensão real das narrativas, mas a realidade de que elas se revestem para o/a entrevistado/a. Além disso, uma história de vida traduz não apenas a verdade subjetiva do/a seu/sua narrador/a, mas também o modo como essa verdade é produzida num momento e num contexto histórico e social particular. Por outras palavras, através do individual é 
possível chegar à compreensão do modo como o universal se manifesta na singularidade: a história de vida permite ao ator organizar e atribuir sentido à sua experiência, estabelecendo e desvendando, ao mesmo tempo, a sua pertença a uma comunidade, a uma cultura, a grupos e/ ou a classes particulares (cf. Brandão, 2007).

\section{Efeitos emocionais e pessoais da rememoração e deontologia profissional}

Precisamente pela sua íntima ligação à identidade, a história de vida envolve aspetos emocionais ligados ao processo de rememoração. Isto é particularmente verdadeiro quando estão em causa "momentos críticos" (Giddens, 1997), "momentos de viragem" (Strauss, 2002), que tendem a constituir acontecimentos estruturantes de um percurso de vida (Bertaux, 1997, p. 71). Para várias entrevistadas, o reconhecimento de uma atração homoerótica constituiu um desses momentos e recordá-lo, assim como os eventos que se lhe seguiram, equivale a revivê-los, a reatualizar sentimentos esquecidos ou a adquirir consciência deles. É isto mesmo que relata Beatriz:

Olhe, nunca pensei que me tivesse sentido tão sozinha durante tanto tempo ou, pelo menos, medo de ficar só... Não é de ficar só, de estar só, de não ter outras pessoas com quem me identificar... Pensei que não fosse durante tanto tempo. Falei em épocas, em fases tão diferentes da minha vida e, por motivos diferentes, fui sentindo esse medo... Nunca tinha pensado nisso!...

(Beatriz, 33 anos, licenciatura)

Por essa razão, a entrevista de história de vida pode ser emocionalmente desorganizadora para o/a entrevistado/a, o que tem, na maioria das vezes, tradução na sua expressão fisionómica, na sua hexis corporal ou em efeitos fisiológicos iniludíveis, como o choro, e cujos impactos a curto, médio e longo prazo o/a investigador/a não controla. Assim, se a atividade profissional dos sociólogos é uma prática social e produz efeitos sociais (APS, 2008, "Preâmbulo"), ela produz também efeitos pessoais variáveis que importa reconhecer e que não se cingem ao momento da recolha de dados. No caso específico desta investigação, foi possível detetar a sua presença não só durante a entrevista, como mostram os exemplos já apresentados, mas também antes e após a sua realização. Assim, Bárbara recorda que, antes de a entrevista ter lugar,

(...) há uma coisa que eu pensei (...) pelo facto de me ser proposto fazer uma história de vida. (...) eu achar que, se tivesse que fazer uma história de vida, (...) ia começar 
com uma breve história, um breve enquadramento dos meus avós, dos meus pais e, depois, eu. (...) Porque uma história de vida começa onde eu nasci, não é? Por isso é que eu me pus a pensar: 'Então, até começava antes!' Os meus avós vêm dali daquela zona e tal, e depois, e depois os outros...

(Bárbara, 31 anos, licenciatura)

A identificação de potenciais entrevistadas seguiu, neste caso, um processo de seleção em bola de neve, o que significa que foram incluídas no estudo algumas mulheres que mantinham entre si relações de proximidade ou mesmo de intimidade. Por isso, a despeito da reserva que lhes foi pedida relativamente ao guião e ao próprio decurso da entrevista, em certos casos, os efeitos desta parecem ter sido claramente identificados por outras entrevistadas. É o caso de Alexandra que, além de afirmar que "Isto é uma revolução! Faz perguntas que nos fazem pensar", sublinha que

A [companheira] bem me dizia! Depois da conversa, eu estava a falar com ela e ela dizia que só pensava na entrevista, só pensava... (...) Eu falava de uma coisa, de vez em quando, e ela estava não sei onde! Estava na entrevista (...)!

(Alexandra, 37 anos, licenciatura)

De facto, como sublinha Bertaux (1997, p. 61), “Este tipo de entrevista é emocionalmente desgastante". Porém, isto não acontece apenas no caso do/a entrevistado/a. Também o/a entrevistador/a, pela necessidade quer de manter uma postura atenta e empática, quer de se posicionar não apenas do ponto de vista do desempenho metodológico, mas também do ponto de vista ético face ao manifesto estado de sofrimento ou desorganização emocional de um/a entrevistado/a, está sujeito a idêntico desgaste. A condução de uma entrevista de investigação pressupõe a capacidade de o/a entrevistador/a manter o seu papel (Ghiglione \& Matalon, 1997), o que implica não ceder à tentação de agir como terapeuta ou conselheiro/a. Porém, o cumprimento das regras metodológicas que garantem o controlo da entrevista não invalida a obrigação moral de contribuir para a estabilização do/a entrevistado/a. Esse equilíbrio delicado pode ser conseguido, como sugere Bertaux (1997, p. 63) de diversas formas: regressando "à evocação de momentos positivos na vida do sujeito", perguntando "qual foi o momento mais feliz ou regressar ao que ele/a considera ser o seu maior sucesso" e aguardando "que o sorriso regresse aos seus olhos".

Outro dos efeitos frequentemente não antecipados - e igualmente problemáti$\cos$ - da entrevista de história de vida é a possibilidade de esta poder contribuir para levar o/a entrevistado/a a ponderar tomar decisões com base no balanço que acaba por fazer da sua vida. Isto significa que o/a entrevistador/a pode vir a ser 
confrontado/a com o conhecimento antecipado de situações que poderão vir a ter efeitos sobre terceiros, mas que estes/as (ainda) desconhecem. Esta questão pode ser especialmente problemática quando está em causa outro/a - potencial ou efetivo/a entrevistado/a na medida em que não pode deixar de interferir na interpretação que o/ a entrevistador/a faz dos próprios dados. Coloca-se, então, a questão de saber o que fazer com informação não solicitada que é frequentemente cedida num estado de fragilidade ou baixa autorregulação. Como lidar com "confissões" ou "revelações" do/a entrevistado/a das quais este/a pode, eventualmente, arrepender-se - ou, não se arrependendo, se e que uso fazer dessa informação?

Se o Código Deontológico dos Sociólogos fornece as diretrizes necessárias à ponderação do que fazer também nesses casos, elas devem ser lidas tendo presente, em primeiro lugar, que a história de vida que obtemos pertence ao/à próprio/a narrador/a. Por isso, subscrevemos as palavras de Denzin (1989, p. 83) quando recorda que "a nossa primeira obrigação é sempre para com a pessoa que estudamos, não para com o nosso projeto ou uma disciplina" e que essa dádiva tem como contrapartida a promessa "de que protegeremos aqueles que as partilham connosco". Neste sentido, como sublinha Atkinson (2002, p. 131), deve ser o/a narrador/a a decidir que informação nos autoriza, ou não, a usar antes de esta ser objeto de qualquer tipo de divulgação.

\section{Conclusões}

As histórias são um dos fundamentos de uma cultura. Elas oferecem leituras particulares do mundo, da nossa sociedade e de nós próprios e obedecem a estruturas narrativas próprias. Entre as muitas histórias que pululam o mundo, a história da nossa vida é fundamental porque é o sustentáculo da nossa identidade. Ser alguém - e ser-se reconhecido/a como alguém diferente dos/as demais - é possuir uma história própria que permite, ao mesmo tempo, dar conta do que fomos e do que queremos ser. Uma história de vida é, assim, um registo da nossa vida e da nossa identidade, mas também da nossa pertença a uma época, a uma sociedade e a uma cultura particulares.

Neste artigo, refletimos sobre algumas implicações epistemológicas, metodológicas e deontológicas da entrevista de história de vida para a investigação sociológica, decorrentes, especificamente, de efeitos como a interrupção da durée, a reorganização de eventos e/ou significados e o risco de imposição de problemática, mas também os efeitos pessoais e emocionais ligados ao processo de rememoração. Para tal, mobilizámos dados de entrevistas cujo guião incluiu questões que tiveram como objeto a própria entrevista. 
O recurso à entrevista de história de vida requer uma compreensão clara da sua natureza. Destacamos, em concreto, o facto de a vida narrada nunca corresponder à vida efetivamente vivida pelo ator, na medida em que envolve, inevitavelmente, uma reinterpretação das ocorrências passadas, da sua sequência e da sua relevância a partir do presente. Neste sentido, a história que recolhemos estará sempre mais ou menos distante da factualidade objetiva da vida a que se refere. Embora tenham sido sugeridas várias estratégias para minorar esse hiato, a relevância dessa ambição depende sempre dos propósitos da nossa investigação. Por outras palavras, a história de vida pode ser usada mais no sentido de captar a verdade do ator do que a sua absoluta conformidade à vida por ele vivida.

Especialmente quando uma história de vida é solicitada, o/a seu/sua narrador/a é levado a encontrar ou a criar ligações, a recordar algo esquecido, a lê-lo noutros moldes. Este aspeto é salientado pelo próprio facto de a situação de entrevista constituir uma situação anómala, marcando um corte no tempo, i.e., no curso "normal" da vida. Se, por um lado, isto abre a possibilidade de revelar a reflexividade do ator, por outro, pode estimulá-la em termos que não são os seus, mas os do/a investigador/a. Neste sentido, impõem-se à sua mobilização os princípios de autovigilância sobre o processo de investigação, nomeadamente, sobre os efeitos possíveis do quadro teórico que mobilizamos e da forma como operacionalizamos os instrumentos de recolha e análise de dados.

O reconhecimento dos efeitos sociais da prática sociológica, salientado no Código Deontológico do Sociólogo, deve, ainda, atender às suas consequências pessoais e individuais. O potencial desorganizador da entrevista de história de vida sobre o/a entrevistado/a ao nível emocional, mas também ao nível das suas relações interpessoais e da sua trajetória de vida sublinha o carácter, de certa forma, partilhado da produção dessa história. O princípio da neutralidade axiológica não pode, por isso, iludir a responsabilidade ética do/a investigador/a daí decorrente. Sobretudo, não deve fazê-lo/a esquecer-se que a história de vida que recolhe pertence, em primeira instância, ao/à seu/sua próprio/a narrador/a, cuja integridade é prioritário preservar.

\section{Notas}

Por decisão pessoal, a autora escreve segundo o novo acordo ortográfico.

1 Na transcrição dos excertos, a indicação (...) refere-se à omissão de uma parcela do texto original.

2 Oartigo de Polletta, Chen, Gardner e Motes (2011) oferece uma síntese crítica da teorização acerca das histórias de vida a partir dessa altura. 
3 Como exemplos de obras de referência que incluíram o recurso a histórias de vida como material empírico primário ou complementar, podem apontar-se Weeks (1990), Faderman (1992), Ponse (1978) ou, mais recentemente, Hammack e Cohler (eds.) (2009). Para o caso português, veja-se Gameiro (1998) e, mais recentemente, Almeida (2010).

4 Veja-se, e.g., Manion e Morgan (2006).

\section{Referências}

Almeida, S. J. (2010). Homossexuais no Estado Novo. Porto: Sextante Editora.

APS. (2008). Código deontológico. Disponível em https://aps.pt/pt/codigo-deontologico/.

Atkinson, R. (2002). The life story interview. Em J. F. Gubrium, \& J. A. Holstein (Eds.), Handbook of interview research (pp. 121-140). Thousand Oaks: Sage.

Bergson, H. (1988). Ensaio sobre os dados imediatos da consciência. Lisboa: Edições 70.

Bertaux, D. (1997). Les récits de vie: Perspective ethnosociologique. Paris: Editions Nathan.

Bourdieu, P. (1986). L'illusion biographique. Actes de la Recherche en Sciences Sociales, 62(1), 72.

Bourdieu, P., Chamboredon, J.-C., \& Passeron, J.-C. (1983). Le métier de sociologue: Préalables épistémologiques. Paris: Mouton Editeur.

Brandão, A. M. (2007). Entre a vida vivida e a vida contada: A história de vida como material primário de investigação sociológica. Configurações, 3, 106.

Brandão, A. M. (2010). "E se tu fosses um rapaz?" Homo-erotismo feminino e construção social da identidade. Porto: Afrontamento.

Caetano, A. (2015). Personal reflexivity and biography: Methodological challenges and strategies. International Journal of Social Research Methodology, 18 (2), 227-242.

Chamberlayne, P., Bornat, J., \& Wengraf, T. (Eds.) (2000). The turn to biographical methods in social science: Comparative issues and examples. Londres \& Nova Iorque: Routledge.

Charmaz, K. (2002). Qualitative interviewing and grounded theory analysis. Em J. F. Gubrium, \& J. A. Holstein (Eds.), Handbook of interview research (pp. 675-694). Thousand Oaks: Sage.

Chauncey, G. (1998). Gay New York. Actes de la Recherche en Sciences Sociales, 125, 9-14.

De Gaulejac, V., \& Legrand, M. (Dir.) (2012). Intervenir par le récit de vie: Entre histoire collective et histoire individuelle. Toulouse: ERES.

Demory, P., \& Pullen, C. (2012). Gay identity, new storytelling and the media. Hampshire \& Nova Iorque: Palgrave MacMillan.

Denzin, N. K. (1989). Interpretive biography. Newbury Park: Sage.

Dwivedi, K. N. (Ed.) (2000). The therapeutic use of stories. Londres: Routledge.

Dwivedi, K. N.; \& Gardner, D. (2000). Theoretical perspectives and clinical approaches. Em K. N. Dwivedi (Ed.). The therapeutic use of stories (pp. 19-41). Londres: Routledge. 
Elias, N. (1989). O processo civilizacional (Vol. I e Vol. II). Lisboa: Dom Quixote.

Erikson, E. H. (1980). Identity and the life cycle. Nova Iorque: W. W. Norton \& Company.

Faderman, L. (1992). Odd girls and twilight lovers: A history of lesbian life in twentieth-century America. s.l.: Penguin Books.

Ferreira, V. (1987). O inquérito por questionário na construção de dados sociológicos. Em A. S. Silva, \& J. M. Pinto (Orgs.), Metodologia das ciências sociais (pp. 165-196). Porto: Afrontamento.

Foucault, M. (1994). História da sexualidade (Vol. I, Vol. II e Vol. III). Lisboa: Relógio d'Água.

Gameiro, O. J. C. (1998). Do acto à identidade: Orientação sexual e estruturação social. (Dissertação de mestrado não publicada). Instituto de Ciências Sociais da Universidade de Lisboa, Lisboa.

Ghiglione, R., \& Matalon, B. (1997). O inquérito: Teoria e prática. Oeiras: Celta Editora.

Giddens, A. (1997). Modernidade e identidade pessoal. Oeiras: Celta Editora.

Gubrium, F., \& Holstein, J. A. (Eds.) (2002). Handbook of interview research. Thousand Oaks: Sage.

Hammack, P. L., \& Cohler, B. J. (Eds.) (2009). The story of sexual identity: Narrative perspectives on the gay and lesbian life course. Nova Iorque: Oxford University Press.

Hoerning, E. M., \& Alheit, P. (1995). Biographical socialization. Current Sociology, $43(2 / 3), 114$.

King, A. (2016). Older lesbian, gay and bisexual adults: Identities, intersections and institutions. Londres \& Nova Iorque: Routledge.

Lieblich, A., Zilber, T. B., \& Tuval-Mashiach, R. (2008). Narrating human actions: The subjective experience of agency, structure, communion, and serendipity. Qualitative Inquiry, 14(4), 613-631.

Manion, A., \& Morgan, R. (2006). The gay and lesbian archives: Documenting same-sexuality in an African context. Agenda, 20(67), 29-35.

Norton, R. (2016). Myth of the modern homosexual: Queer history and the search for cultural unity. Londres \& Nova Iorque: Bloomsbury Publishing.

Plummer, K. (Ed.) (1993). Modern homosexualities: Fragments of lesbian and gay experience. Londres: Routledge.

Plummer, K. (2001). Documents of life 2: An invitation to a critical humanism. Londres: Sage.

Plummer, K. (2002). Telling sexual stories: Power, change and social worlds. Londres: Routledge.

Polletta, F., Chen, P. C. B., Gardner, B. G., \& Motes, A. (2011). The sociology of storytelling. Annual Review of Sociology, 37, 109-130.

Ponse, B. (1978). Identities in the lesbian world: The social construction of self. Westport: Greenwood Press.

Roulston, K. (2014). Interactional problems in research interviews. Qualitative Research, 14(3), 277-293.

Schütz, A. (2001). Choosing among projects of action. Em J. Alexander (Ed.), Mainstream and critical social theory: Classical, modern and contemporary (Vol. II) (pp. 332-355). Londres: Sage. 
Strauss, A. L. (2002). Mirrors and masks: The search for identity. New Brunswick: Transaction Publishers.

Tap, P. (1981). Identité, identification et représentations de sexe: Approches pour une étude de la personnalisation de l'acteur social (Thèse de Doctorat d'Etat). Université de Paris-Nanterre, Paris.

Tap, P. (1996). A sociedade Pigmaleão: Integração social e realização da pessoa. Lisboa: Instituto Piaget.

Thomas, W.I., \& Znaniecki, F. (1958). The Polish peasant in Europe and America I. Nova Iorque: Dover Publications.

Van der Maren, J.-M. (2010). Le souvenir et le bouleversement du temps dans la reconstruction du passé: Réflexions méthodologiques, Recherches Qualitatives, 8, 37-50.

Weeks, J. (1990). Coming out: Homosexual politics in Britain from the nineteenth century to the present. Londres: Quartet Books.

Data de submissão: 11/06/2019 | Data de aceitação: 04/10/2019 